SILVA, C.R.A. et al. Persistência do quarto arco aórtico direito em um cão - Relato de caso. PUBVET, Londrina, V. 6, N. 4, Ed. 191, Art. 1288, 2012.

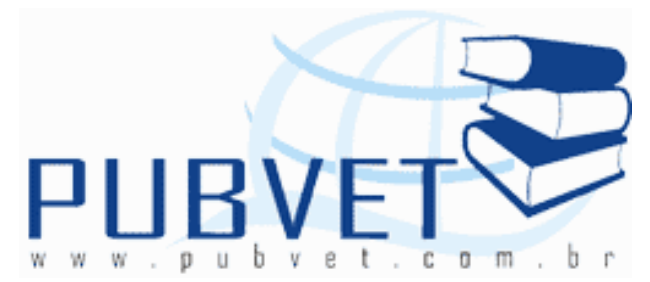

PUBVET, Publicações em Medicina Veterinária e Zootecnia.

\title{
Persistência do quarto arco aórtico direito em um cão - Relato de caso
}

\author{
Catarina Rafaela Alves da Silva ${ }^{1}$; Deyse Naira Mascarenhas Costa ${ }^{2}$; Marcos \\ Daniel de Sousa Ferreira²; Francisco Lima Silva; Amilton Paulo Raposo Costa ${ }^{3}$ \\ ${ }^{1}$ Doutoranda em Ciência Animal - UFPI \\ ${ }^{2}$ Mestrando (a) em Ciência Animal - UFPI \\ ${ }^{3}$ Professor Doutor Universidade Federal do Piauí.
}

\section{Resumo}

Este trabalho descreve um caso de persistência do arco aórtico direito em um canino de 5 meses de idade, macho da raça pastor alemão atendido na Clínica Animal's em Teresina-PI. O animal apresentava sinais de regurgitação freqüente logo após se alimentar. Anomalia do anel vascular foi diagnosticada pela constrição do esôfago na base cardíaca através de exame radiográfico contrastado. O animal foi submetido ao tratamento que consistiu em: Procedimento cirúrgico precedido por medicação pré-anestésica, Terapia antiinflamatória e Antibioticoterapia. Conclui-se, portanto que a correção da persistência do quarto arco aórtico direito, propicia a redução gradual do megaesôfago nas semanas subseqüentes à realização da cirurgia, reduzindo a ocorrência de regurgitações proporcionando melhoria na qualidade de vida do animal.

Palavras-chave: cardiovascular, anel vascular, isoflourano 
SILVA, C.R.A. et al. Persistência do quarto arco aórtico direito em um cão - Relato de caso.

PUBVET, Londrina, V. 6, N. 4, Ed. 191, Art. 1288, 2012.

\title{
Persistence fourth right aortic arch in a dog law - Case report
}

\begin{abstract}
This paper describes a case of persistent right aortic arch in a canine 5-monthold male German Shepherd Animal Clinic's served in Teresina-PI. The animal showed signs of regurgitation soon after eating. Vascular ring anomaly was diagnosed by constriction of the esophagus through the cardiac base contrast cystography. The animal was subjected to treatment that consisted of: A surgical procedure preceded by premedicated, anti-inflammatory and antibiotic therapy. It follows therefore that the correction of persistent right fourth aortic arch leads to the gradual reduction of megaesophagus in the weeks subsequent to surgery, reducing the occurrence of regurgitation providing better quality of life of the animal.
\end{abstract}

Keywords: cardiovascular, vacular rings, isofluorane

\section{REVISÃO DE LITERATURA}

As anomalias dos anéis vasculares são alterações congênitas provocadas por defeitos na embriogênese dos arcos aórticos. A presença destas más formações ocasiona a compressão extraluminal esofágica ao nível da base cardíaca (RICARDO et al., 2001).

O diagnóstico é firmado pela radiografia contrastada do esôfago que irá apresentar além do megaesôfago, também uma contrição esofágica na base cardíaca (FARROW, 2003). A realização precoce da cirurgia evita danos maiores ao esôfago, ou seja, possibilitará uma menor chance de megaesôfago irreversível e perda da motilidade esofágica (ARCINIEGAS et al., 1979; TWEDT, 1997). Na presença de pneumonia, esta patologia deve ser tratada antes da intervenção cirúrgica para correção do anel vascular (FINGEROTH, 1998).

A persistência do arco aórtico direito é a anomalia do anel vascular mais encontrada em cães, diagnosticada em $95 \%$ dos casos, ocorrendo quando o quarto arco aórtico direito persiste ao invés do quarto arco aórtico esquerdo 
SILVA, C.R.A. et al. Persistência do quarto arco aórtico direito em um cão - Relato de caso.

PUBVET, Londrina, V. 6, N. 4, Ed. 191, Art. 1288, 2012.

que formaria a aorta (ELLISON, 1996; FINGEROTH \&FOSSUM, 1987;JONES et al., 2000).

Este trabalho objetivou relatar o tratamento de um caso de persistência do quarto arco aórtico direito em um cão da raça Pastor Alemão atendido na Clínica Animal's da cidade de Teresina-Piauí.

\section{DESCRIÇÃO DO CASO}

Foi atendido na Clínica Animal's, um canino, macho, 5 meses de idade, raça Pastor Alemão com queixa de regurgitação ao se alimentar. Ao exame clínico não foram observadas alterações vísíveis, as mucosas estavam normocoradas, freqüência cardíaca, respiratórias e temperatura retal normais. Diante do exposto, foram realizados exames laboratoriais e radiográficos para uma maior averiguação. Os valores dos exames laboratoriais estavam normais para espécie sendo o diagnóstico confirmado através de radiografia contrastada do esôfago, no qual permitiu a visualização de megaesôfago e constrição da base cardíaca sugerindo uma anomalia do anel vascular.

O animal foi submetido ao procedimento cirúrgico e o protocolo anestésico consistiu como Medicação Pré Anestésica (MPA): cloridrato de tramadol ( $2 \mathrm{mg} / \mathrm{kg} / \mathrm{IM})$. Foi realizada terapia antiinflamatória com Meloxicam $(0,2 \mathrm{mg} / \mathrm{kg} / \mathrm{SC})$ e antibioticoterapia com Penicilina Benzatina (40.000 UI/ $\mathrm{kg} / \mathrm{IM})$.

A indução anestésica foi realizada com diazepam $(0,5 \mathrm{mg} / \mathrm{kg} / \mathrm{IV})$ e propofol ( $3 \mathrm{mg} / \mathrm{kg} / \mathrm{IV}$ ) lento, seguido de intubação endotraqueal, e manutenção anestésica por meio de anestesia inalatória com Isofluorano. Houve depressão respiratória no animal no transanestésico, no qual fora submetido através de respiração assistida e monitoração cardíaca por meio de um monitor cardíaco multiparamétrico a $50 \mathrm{~mm} / \mathrm{s}$, modo $\mathrm{N}$ e derivação $\mathrm{I}$.

A frequência cardíaca permaneceu dentro de um limite de 162 a 204 bpm e a saturação de oxigênio $\left(\mathrm{SpO}_{2}\right)$ em um valor entre 86 a 98. A temperatura retal foi aferida a cada 10 minutos, permanecendo em uma média de $37^{\circ} \mathrm{C}$. Após o término da cirurgia foi realizado um bloqueio entre a incisão 
SILVA, C.R.A. et al. Persistência do quarto arco aórtico direito em um cão - Relato de caso. PUBVET, Londrina, V. 6, N. 4, Ed. 191, Art. 1288, 2012.

cirúrgica realizado no primeiro e quinto espaço intercostal com o uso de lidocaína sem vasoconstrictor, aplicado por via subcutânea. A pressão negativa foi restabelecida por meio de toracocentese para uma melhor estabilização do animal, simultaneamente a uma redução gradativa da vaporização do anestésico para uma redução da CAM e que o animal pudesse retornar a respirar, sendo isto observado após 20 minutos, ainda permanecendo assistido até a total recuperação anestésica. Depois de 15 dias pós cirurgia o animal retornou com histórico de regurgitação, mas não foi constatada nenhuma complicação pós-cirúgica recebendo alta em poucos dias.

\section{DISCUSSÃO E CONCLUSÃO}

A presença de regurgitações, logo após o período cirúrgico pôde ser observado por alguns autores e sua ocorrência tende a diminuir com a redução de megaesôfago (MULDOON et al. 1997).

O uso do propofol na indução anestésica garantiu uma maior segurança ao procedimento, uma vez que é um fármaco que pode ser utilizado em cirurgias de pacientes de risco. A manutenção com a anestesia inalatória com Isofluorano possibilitou menos riscos cardiovasculares uma vez que não expõe o miocárdio à ação das catecolaminas e por ter baixa excreção renal e hepática, com isso possibilitando ao animal estabilidade nos parâmetros cardiovasculares durante 0 procedimento anestésico (FANTONI \& CORTOPASSI, 2009)

Conclui-se, portanto que a correção da persistência do quarto arco aórtico direito, propicia a redução gradual do megaesôfago nas semanas subseqüentes à realização da cirurgia, reduzindo a ocorrência de regurgitações proporcionando melhoria na qualidade de vida do animal.

\section{REFERÊNCIAS}

ARCINIEGAS, E.; HAIMI, M.; HERTZLER, J.H.; et al. Surgical management of congenital vascular rings. J. Thorac. Cardiovasc. Surg. v.77, n.5,p.721-727, 1979 . 
ELLISON, G.W. Correção cirúrgica do arco aórtico direito persistente. In: BOJRAB, M..J. Técnicas Atuais em Cirurgia de Pequenos Animais. São Paulo: Roca, 1996.

FANTONI,D.T;CORTOPASSI,S.R.G. Anestesia em cães e gatos. 2.ed. São Paulo: Roca, 2009.

FARROW, C.S. Veterinary Diagnostic Imaging the Dog and Cat. St. Louis: Mosby, 2003.

FINGEROTH, J.M.; FOSSUM, T.W. Lateonset regurgitation associated with persistent right aortic arch in two dogs. J. Am. Vet. Med. Assoc. v.191, n.12, p.981- 983, 1987.

FINGEROTH, J.M. Afecções cirúrgicas do esôfago. In: SLATTER, D. Manual de Cirurgia de Pequenos Animais. São Paulo: Manole, 1998.

JONES, T.C.; HUNT, R.D.; KING, N.W.Patologia Veterinária. 6.ed. São Paulo: Manole, 2000.

MULDOON, M.M.; BIRCHARD, S.J., ELLISON, G.W. Long-term results of surgical correction of persistent right aortic arch in dogs: 25 cases (1980-1995). J. Am. Vet. Med. Assoc. v.10, n.2, p.1761-1763, 1997.

RICARDO, C.; AUguSto, A.; CANAVESE, S. et al. Double aortic arch in a dog (Canis familiaris): a case report. Anatom., Histol., Embryol. v.30, n.6, p.379-381, 2001.

TWEDT, D.C. Afecções do esôfago. In: ETTINGER, S.J., FELDMAN, E.C. Tratado de Medicina Interna Veterinária. 4.ed. São Paulo: Manole, 1997. 